Johannes Weber

\title{
Gesellschaftsrecht und Gläubigerschutz im Internationalen Zivilverfahrensrecht
}

Die Internationale Zuständigkeit bei Klagen gegen Gesellschafter und Gesellschaftsorgane vor und in der Insolvenz

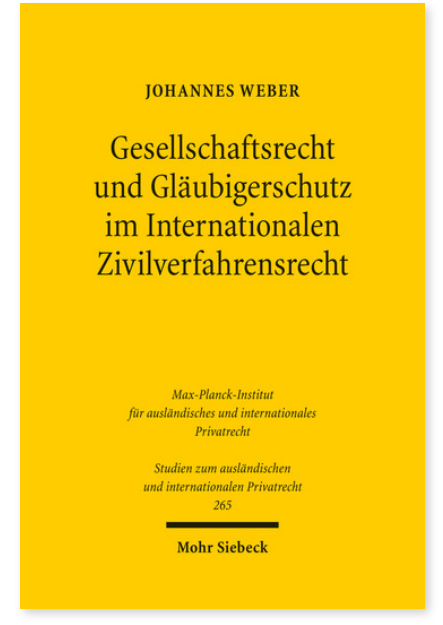

2011. XXIV, 567 Seiten. StudIPR 265

ISBN 978-3-16-151768-6

DOI 10.1628/978-3-16-151768-6

eBook PDF $114,00 €$

ISBN 978-3-16-150914-8

fadengeheftete Broschur 114,00€
Welche Gerichte sind international zuständig, wenn es um die Durchsetzung von Normen des Gläubigerschutzes in Gesellschaften geht? Johannes Weber untersucht diese Frage mit Blick auf das Europäische Internationale Zivilverfahrensrecht unter Einbeziehung des deutschen und englischen Sachrechts. Er analysiert zunächst das zuständigkeitspolitische Spannungsfeld bei gesellschafts- und insolvenzrechtlichen Fragestellungen und stellt die Weichen für die Abgrenzung von EulnsVO und EuGVVO. Sodann nimmt er die Zuständigkeitsnormen der EuGVVO näher in den Blick. Eine ökonomische Betrachtung des Gläubigerschutzes erweist sich dabei als wichtiges Hilfsmittel, um die Systembegriffe des Europäischen IZVR autonom auszulegen. Der Autor zeigt außerdem Reformperspektiven für die künftige Rechtsentwicklung auf.

Johannes Weber Geboren 1982; Studium der Rechtswissenschaft in Freiburg und Cambridge (LL.M.); 2011 Promotion; wissenschaftlicher Assistent am Max-Planck-Institut für ausländisches und internationales Privatrecht; Rechtsreferendar am Hanseatischen Oberlandesgericht.

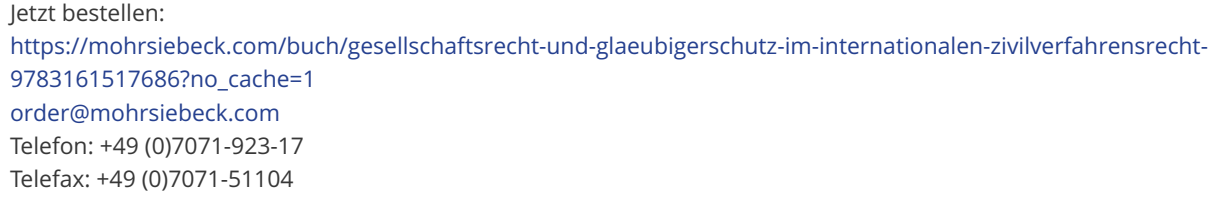

